\begin{tabular}{|c|c|}
\hline Title & Self-Healing Behaviors of Tough Polyampholyte Hydrogels \\
\hline Author(s) & $\begin{array}{l}\text { Ihsan, A bu Bin; Sun, T ao Lin; Kurokawa, Takayuki; Karobi, Sadia Nazneen; Nakaj ima, Tasuku; Nonoyama, T akayuki; } \\
\text { Roy, Chanchal Kumar; Luo, Feng; Gong, Jian Ping }\end{array}$ \\
\hline Citation & $\begin{array}{l}\text { Macromolecules, 49(11), 4245-4252 } \\
\text { https://doi.org/10.1021/acs.macromol.6b00437 }\end{array}$ \\
\hline Issue Date & $2016-06-14$ \\
\hline Doc URL & http://hdl.handle.net/2115/65545 \\
\hline Rights & $\begin{array}{l}\text { This document is the A ccepted Manuscript version of a Published Work that appeared in final form in Macromolecules, } \\
\text { copyright } \mathrm{O} 2016 \text { A merican Chemical Society after peer review and technical editing by the publisher. To access the } \\
\text { final edited and published work see http://pubs.acs.org/doi/pdf/10.1021/acs.macromol.6b00437 }\end{array}$ \\
\hline Tyре & article (author version) \\
\hline Additional Information & There are other files related to this item in HUSCAP. Check the above URL. \\
\hline File Information & Manuscript-jornal.pdf ( ) \\
\hline
\end{tabular}

Instructions for use 


\title{
Self-healing Behaviors of Tough Polyampholyte Hydrogels
}

Abu Bin Ihsan ${ }^{1 \S}$, Tao Lin Sun ${ }^{1,2,}$, Takayuki Kurokawa ${ }^{1,2}$, Sadia Nazneen Karobi ${ }^{3}$, Tasuku Nakajima $^{1,2}$, Takayuki Nonoyama ${ }^{1,2}$, Chanchal Kumar Roy ${ }^{1}$, Feng Luo $^{1}$, Jian Ping Gong ${ }^{1,2^{*}}$

${ }^{1}$ Faculty of Advanced Life Science, Hokkaido University, Sapporo 060-0810, Japan

${ }^{2}$ Global Station for Soft Matter, Global Institution for Collaborative Research and Education (GI-CoRE), Hokkaido University, Sapporo 060-0810, Japan

${ }^{3}$ Graduate School of Life Science, Hokkaido University, Sapporo 060-0810, Japan

$\S:$ Authors equally contributed.

*: Author to whom correspondence should be addressed.

Tel \& FAX: +81-(0)11-706-2774, E-mail: gong@ mail.sci.hokudai.ac.jp.

Key Words: Polyampholyte hydrogel; Toughness; Self-healing; Ionic bond

\begin{abstract}
Recently, polyampolytes have been discovered to form hydrogels that possess high toughness, full resilience, and self-healing between two cut surfaces. The self-healing of this class of hydrogels is based on the reforming of the multiple ionic bonds at the fractured surfaces, in which the mobility of the polymer segments and strength of the ionic bonds play an important role. In this work, we study the effects of healing temperature, and chemistry of the polyampholyte hydrogels (chemical cross-linker density and chemical structure of the monomers) on the healing kinetics and healing efficiency. The high healing temperature substantially accelerates the self-healing kinetics. Chemical crosslinking reduces the selfhealing efficiency. Monomers with more hydrophobic feature give a low self-healing efficiency. For polyampholyte physical hydrogels with a softening temperature below the room temperature, excellent healing efficiency ( $84 \%$ on average and maximum $99 \%)$ was
\end{abstract}


observed without any external stimuli. We found a correlation between the self-healing efficiency and the fraction of dynamic bonds in the total bonds for relatively soft samples, which is an evidence that the self-healing is due to the reforming of dynamic bonds.

\section{Introduction}

Living tissues, which exhibit high toughness and excellent mechanical properties, have an amazing ability to endure autonomous healing and repairing when they undergo damage. ${ }^{1}$ For example, a cut or wounded part of living body heals with time by cell migration from the adjacent tissues followed by cell proliferation and remodeling ${ }^{2,3}$. The question that is repeatedly asked is whether one could mimic high toughness and self-healing in tissue-like synthetic materials of hydrogels that are crosslinked polymers containing water. Most of synthetic hydrogels, either physically or chemically crosslinked, are weak materials due to negligible internal energy dissipation. Furthermore, they are unable to self-repair to their original state once the structure is damaged due to lacking of bond reforming mechanism after rupture. Intensive efforts have been made so far to develop self-healing hydrogels by incorporating structure-reforming mechanism at the ruptured interface, including reforming of physical bond, ${ }^{4-17}$ molecular recognition, ${ }^{18-22}$ and chemical bond formation. ${ }^{23}$ Among these works, some of them succeeded in obtaining hydrogels with both high toughness and

self-healing efficiency. ${ }^{6,14,18}$ In most cases, however, the hydrogels were mechanically too weak to characterize the healing performance quantitatively, needless to say for practical application as load-bearing soft materials, such as artificial cartilages. ${ }^{4,71,16}$ Designing various kinds of hydrogels possessing self-healing properties, along with high toughness and biocompatibility will substantially broaden the potential use of the material.

The strategy to design polymer hydrogels of multiple high mechanical performances, including a proper modulus, high strength and toughness, high fatigue resistance, and selfhealing, is to introduce the reversible weak bonds (sacrificial bonds) in the materials along 
with the strong bonds. The strong bonds, either covalent or non-covalent, form the primary structure, maintaining the integrity of the material. The weak bonds, on the other hand, rupture upon stress to dissipate energy, imparting toughness of the materials. ${ }^{24-29}$ Reforming of dynamic weak bonds after rupture imparts internal self-recovery and surface self-healing of the damaged materials.

Based on this strong/weak bonds concept, we recently developed a novel class of supramolecular hydrogels possessing high toughness and self-healing from neutral polyampholytes. ${ }^{27,28}$ This class of polyampholyte hydrogels is synthesized by copolymerizing charge balanced amount of oppositely charged monomers at high concentration so that the polymer chains entangled to form gels. The randomness of charge distribution on the polyampholyte chains leads to the formation of multiple ionic bonds, both of intra-chains and inter-chains, with wide distribution of strength. The strong ionic bonds of inter-chains, stabilized by entanglements, play the role of permanent crosslinking while the weak ionic bonds, both inter-chain and intra-chain, serve as dynamic and reversible sacrificial bonds to dissipate energy. ${ }^{30}$ As the weak ionic bonds rupture and reform reversibly, the polyampholyte hydrogels, having 50-60wt\% of water, exhibit high toughness (fracture energy $\sim 4000 \mathrm{~J} / \mathrm{m}^{2}$ ), full self-recovery (self-resilience) after large deformation. Depending on the chemical structure of the ion pairs, different levels of self-healing have also been observed between two cut surfaces for these polyampholyte hydrogels. ${ }^{27}$

Although many supramolecular hydrogels with reversible dynamic bonds, such as the hydrogen bonds, ionic bonds, and hydrophobic interaction, etc., have been reported, less work has been report to relate the self-healing efficiency quantitatively to the molecular structrue. ${ }^{11,14,27}$

In this paper, we intend to correlate the self-healing efficiency with the structure of supramolecular gels using polyampholyte hydrogels as a model system. In principle, when 
being cut at a not very high rate so that the ionic bonds have enough time to exchange their partners, the gel breaks most probably by the rupture of ionic bonds that have bond strength much weaker than the covalent bonds. By contacting the fractured surfaces, a large number of damaged ionic bonds in the vicinity of surfaces reform across the interface which heals the sample (Scheme 1a). For an efficient healing, proper mobility of the polymer segments and strength of the ionic bonds are required. So, in this work we study the effects of healing temperature and chemistry (cross-linker density and monomer chemical structure) on the selfhealing of polyampholyte hydrogels. The results show that the self-healing efficiency is related to the fraction of dynamic weak bonds to total bonds in the polyampholyte hydrogels, for the relatively soft hydrogels. This work gives insight to understand the self-healing mechanism and to design supramolecular hydrogels possessing both high toughness and selfhealing efficiency. 
a

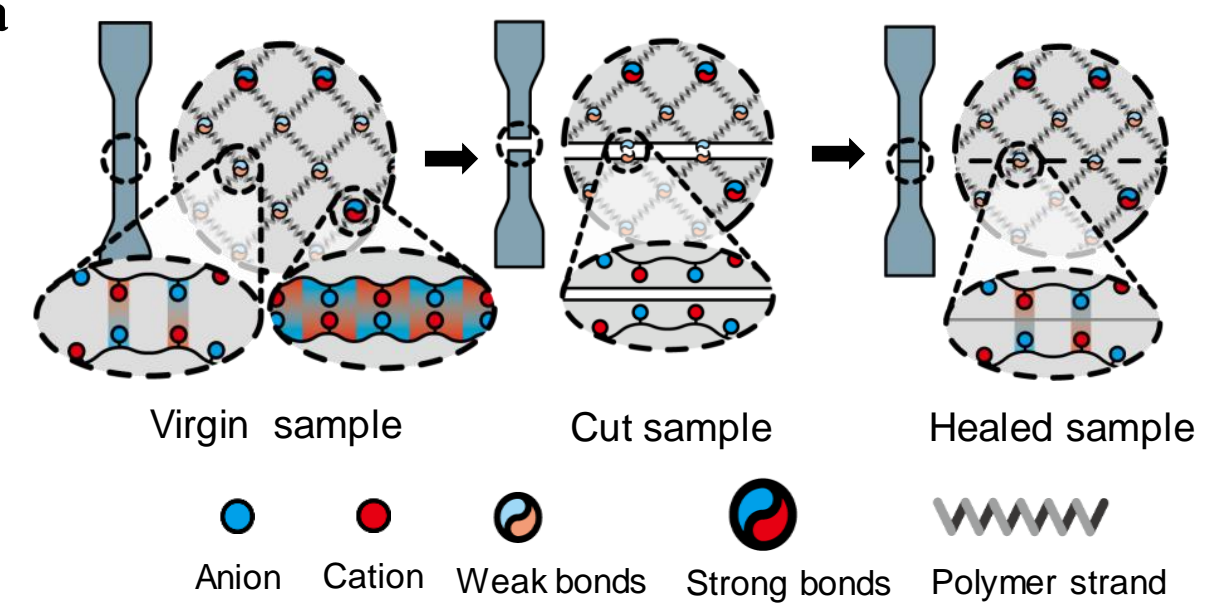

b

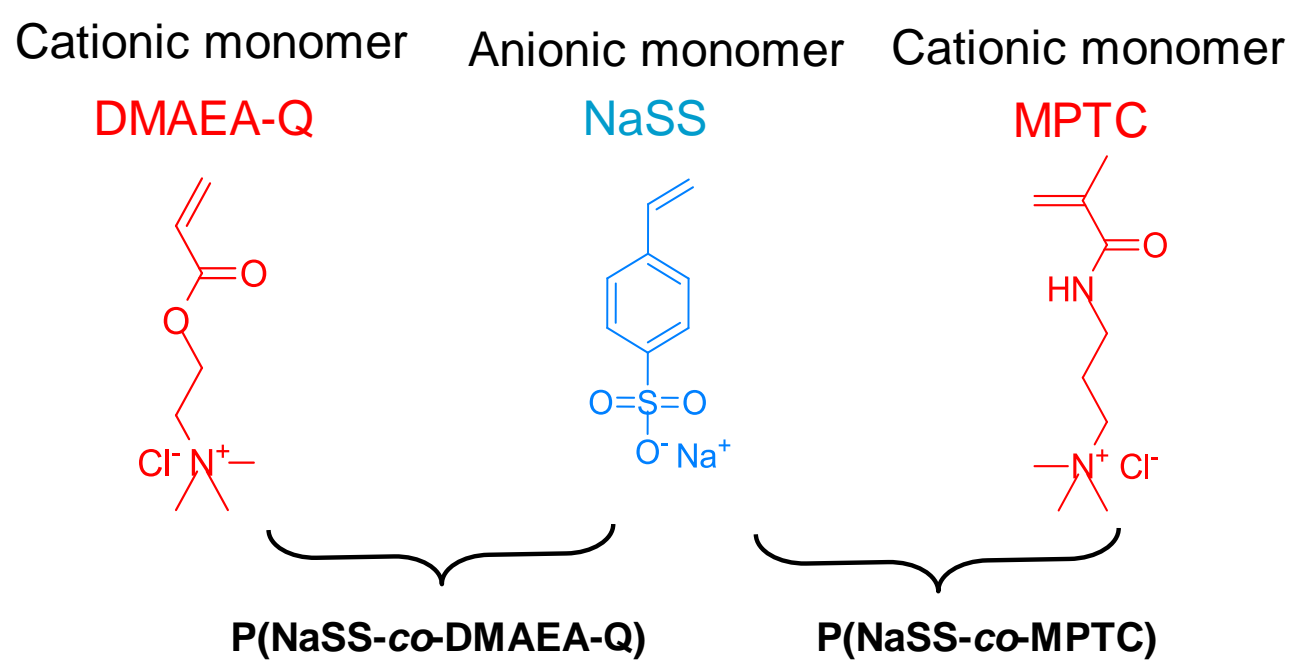

Scheme 1. Schematic illustration of a possible self-healing mechanism of polyampholyte

hydrogels. a, Many ionic bonds of different strength are formed in polyampholyte hydrogels.

For a certain observation time, the strong ionic bonds serve as permanent crosslinking points as like the covalent crosslinking as well as the trapped entanglements, imparting elasticity, and the weak ionic bonds rupture and reform under the deformation, imparting toughness and self-healing. When the virgin sample is cut, both the weak ionic bonds and the strong ionic bonds are ruptured on the cut surfaces. After contacting the cut surfaces, the weak bonds with very high dynamics immediately form bridges across the interface, imparting self-healing. Soft samples having a large amount of weak bonds show the high healing efficiency, along with high toughness. b, Chemical structures of anionic monomer NaSS, cationic monomers DMAEA-Q and MPTC used for synthesizing polyampholyte hydrogels, P(NaSS-co- 
DMAEA-Q) and P(NaSS-co-MPTC). P(NaSS-co-DMAEA-Q) and P(NaSS-co-MPTC) samples are denoted PA- $C_{M B A A}$ and $\mathrm{PA}^{*}-C_{M B A A}$, respectively, where $C_{M B A A}$ is the chemical crosslinker density $(\mathrm{mol} \%)$.

\section{Experimental section}

\section{Synthesis of hydrogels}

The polyampholyte gel $\mathrm{P}(\mathrm{NaSS}-\mathrm{co}$-DMAEA-Q) was synthesized by one-step random copolymerization from precursor aqueous solution containing $1.04 \mathrm{M} \mathrm{NaSS}, 0.96 \mathrm{M}$ DMAEA-Q (Scheme 1b), 0-4 mol\% chemical cross-linker MBAA, 0.1mol\% a-ketoglutaric acid (both relative to the total monomer concentration of $2 \mathrm{M}$ ), and $0.5 \mathrm{M} \mathrm{NaCl}$. This monomer composition gave true 1:1 charge ratio in the final hydrogel, as confirmed by the elementary analysis. ${ }^{28}$ The solution was injected into a reaction cell $(10 \mathrm{~cm} \times 10 \mathrm{~cm})$ consisting of a pair of parallel glass plates separated by silicone spacer with various thickness ( 1-5 mm). The precursor solution was purged in argon atmosphere to remove dissolved oxygen and polymerization of the hydrogel was carried out in argon atmosphere in which the oxygen concentration was less than $0.1 \mathrm{ppm}$ by irradiating UV light $(365 \mathrm{~nm})$ from the both side of the reaction cell for $8 \mathrm{hrs}$.

After polymerization, the gel was immersed in de-ionized water for at least one week, and the water was changed every day. The sample shrank in water from its as-prepared sample by $40 \%$ in volume. During this process, the mobile counter-ions and co-ions of the sample were dialyzed away from the hydrogel, which substantially stabilizes both the intra- and interchain ionic complexes to form a tough hydrogel. The samples are coded as PA- $C_{M B A A}$, where $C_{\mathrm{MBAA}}$ indicates the chemical cross-linker density (mol\%). The polyampholyte gel P(NaSSco-MPTC) was also synthesized from the solution of 1.09 M NaSS and 1.01 M cationic monomer 3-(methacryloylamino)propyl-trimethylammonium chloride (MPTC), 0.25 mol\% UV initiator, 2-oxoglutaric acid (in relative to total monomer concentration of $2.1 \mathrm{M}$ ), and 0.5 
$\mathrm{M} \mathrm{NaCl}$. After synthesis, the samples were also washed in water. The P(NaSS-co-MPTC) samples were coded as $\mathrm{PA}^{*}-0$ since no chemical crosslinker was added.

\section{Water content measurement}

The water content of the samples was measured by the weight change upon drying using the moisture balance (Moisture balance; MOC-120H, SHIMADZU Co.). Before weighing the weight of swollen gel, the excess water on the gel surface was gently absorbed by using a kimwipes. The drying sample was obtained by evaporate the water in the gel at an elevated temperature of $(30-120){ }^{\circ} \mathrm{C}$. The water content $C(\mathrm{wt} \%)$ is defined as the ratio percentage between the weight of water in gel to the total weight of the gel.

$C(\mathrm{wt} \%)=\frac{\text { weight of water }}{\text { total weight of gel }} \times 100 \%$

\section{Mechanical analysis}

After reaching swelling equilibrium, the tensile test was performed with a commercial test machine (Tensilon RTC-1310A, Orientec Co.). For the tensile test, the PA- $C_{\text {MBAA }}$ gels with a thickness of 1.3 to $2.8 \mathrm{~mm}$ were cut into a dumbbell shape standardized as JIS-K6251-7 sizes ( $4 \mathrm{~mm}$ in inner width and $15 \mathrm{~mm}$ in gauge length $L_{0}$ ) with a gel cutting machine (Dumb Bell Co., Ltd). Both ends of the dumbbell-shaped samples were clamped and stretched at a constant velocity $v, 10 \mathrm{~mm} / \mathrm{min}$., corresponding to the strain rate, $\dot{\varepsilon}=\frac{v}{L_{0}}=0.011 \mathrm{~s}^{-1}$. The elastic modulus, $E$, was calculated by using the initial small strain data of the stress-strain curves (within 10\%). The work of extension for fracture $W_{\text {ext }}\left(\mathrm{J} / \mathrm{m}^{3}\right)$, a parameter indicating the work required to fracture the sample per unit volume, was calculated from the area below the tensile stress-strain curve until fracture. The fracture stress $\sigma_{b}$ and fracture strain $\varepsilon_{b}$ are the nominal values at the breaking point. For the $\mathrm{PA}^{*}-0$ gel, the geometry of the sample for tensile test is $2 \mathrm{~mm}$ in inner width and $12 \mathrm{~mm}$ in gauge length. The sample stretched at a constant velocity $v, 100 \mathrm{~mm} / \mathrm{min}$, corresponding to the strain rate $0.14 \mathrm{~s}^{-1}$. 


\section{Transmittance measurement}

The light absorbance $A$ of gel was characterized using Shimadzu UV Spectrophotometer (UV-1800) at a wavelength of $578 \mathrm{~nm}$. The transmittance $T$ of gel was calculated from absorbance $A$ from the equation $\mathrm{T} \%=10^{-A} \times 100$. The experiment was performed in water during heating and cooling of sample in the temperature range $\left(2-70^{\circ} \mathrm{C}\right)$.

\section{Dynamic test}

The dynamic test was performed by using an ARES rheometer (advanced rheometric expansion system, Rheometric Scientific Inc.). The disk sample with a diameter $15 \mathrm{~mm}$ and a thickness $2.8 \mathrm{~mm}$ was fixed between the metal plates by glue. In order to prevent the water evaporating from the gel, the sample was surrounded by water during the measurement. A rheological frequency sweep from 0.01 to $10 \mathrm{~Hz}$ was performed at a shear strain of $0.5 \%$ at different temperatures from $0.1^{\circ} \mathrm{C}$ to $80^{\circ} \mathrm{C}$.

\section{Self-healing efficiency}

The self-healing behaviors were characterized by comparing the tensile fracture behaviors of the virgin sample and the healed sample. The PA- $C_{\mathrm{MBAA}}$ gels in swelling equilibrium with thickness of 1.3-4.8 mm were cut into a dumbbell shape standardized as IEC-540 sizes (4 mm width and $20 \mathrm{~mm}$ in gauge length) with a gel cutting machine (Dumb Bell Co., Ltd). Dumbbell shape gel was cut in the middle into two pieces in air, and the cut parts were brought into contact at $25^{\circ} \mathrm{C}$ immediately after being cut and were placed in a rubber frame having a size just fitting the dumbbell shape gel. In order to ensure contact between cut surfaces, a slight handing pressure $\left(\sim 10^{4} \mathrm{~Pa}\right)$ was applied to the two cut pieces when connecting the cut samples. During the mending process, no stress was applied on the interface. To prevent the gel from swelling due to thermal effect, the frame was embedded in the middle of two glass plates. And then, the system was immersed in water bath for mending at a prescribed temperature $\left(4^{\circ} \mathrm{C}, 25^{\circ} \mathrm{C}, 37^{\circ} \mathrm{C}, 50^{\circ} \mathrm{C}\right)$. After different mending time, the 
samples were taken out from the mending bath and the tensile test was performed at ambient temperature immediately. To estimate the self-healing efficiency, virgin samples as reference samples were also stored in the same water bath at the corresponding temperature, and the storing time is set to the corresponding saturated healing time before being performed the same tensile test. The healing efficiency $\left(\eta_{\mathrm{w}}, \eta_{\sigma}, \eta_{\varepsilon}\right)$ was defined as the ratio of work of extension for mended $W_{\text {ext,mended}}$, fracture stress for mended $\sigma_{\mathrm{b} \text {,mended, and fracture strain for }}$ mended $\varepsilon_{\mathrm{b}, \text { mended }}$ to the virgin samples $W_{\text {ext,virgin }}, \sigma_{\mathrm{b}, \text { virgin }}$ and $\varepsilon_{\mathrm{b}, \text { virgin }}$, respectively, as follows: $\eta_{\mathrm{w}}=W_{\text {ext,mended }} / W_{\text {ext,virgin }} \times 100, \eta_{\sigma}=\sigma_{\mathrm{b}, \text { mended }} / \sigma_{\mathrm{b}, \text { virgin }} \times 100 \%$, and $\eta_{\varepsilon}=\varepsilon_{\mathrm{b}, \text { mended }} / \varepsilon_{\mathrm{b}, \text { virgin }} \times 100 \%$. For the self-healing experiments of $\mathrm{PA}^{*}-0$ gels, the geometry of the samples used was $2 \mathrm{~mm}$ width and $12 \mathrm{~mm}$ in gauge length. The mending temperature was set at $25^{\circ} \mathrm{C}$ and $55^{\circ} \mathrm{C}$ in water bath.

\section{Results}

\section{Effect of temperature}

We start with the $\mathrm{P}(\mathrm{NaSS}-\mathrm{co}$-DMAEA-Q) system. As a typical example, we first discuss the weakly crosslinked sample PA- 0.1 with $0.1 \mathrm{~mol} \%$ crosslinker. It was soft and highly stretchable, having a Young's modulus of $E=0.08 \mathrm{MPa}$ and tensile fracture strain $\varepsilon_{b}=32.64$. As the dynamic features of ionic bonds, the gel showed the large hysteresis in its loading and unloading curves with a residual strain. For a moderate elongation, the sample showed full recovery to its virgin state after certain waiting time. ${ }^{28}$ The sample was transparent at high temperature, and turbid at low temperature (inserted images in Fig. 1a). The transmittance of the sample at $578 \mathrm{~nm}$ showed a sharp transition around $10-15^{\circ} \mathrm{C}$ (Fig. 1a), indicating the structure change with the temperature. The thermal energy causes the rupture of ionic bonds and increases the dynamics of polymer segments, therefore the polyampholyte hydrogel exhibits a thermo-responsive behavior with an upper critical solution temperature (UCST 
$12^{\circ} \mathrm{C}$ at the $50 \%$ transmittance), as confirmed by the temperature dependence of the storage modulus $\left(G^{\prime}\right)$, the loss modulus $\left(G^{\prime \prime}\right)$, and $\tan \delta$ of the sample (Fig. 1b).

$\mathbf{a}$

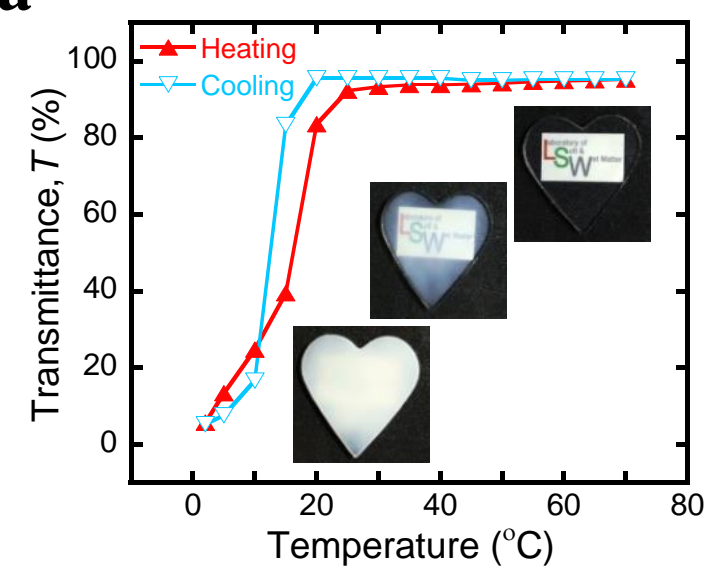

b

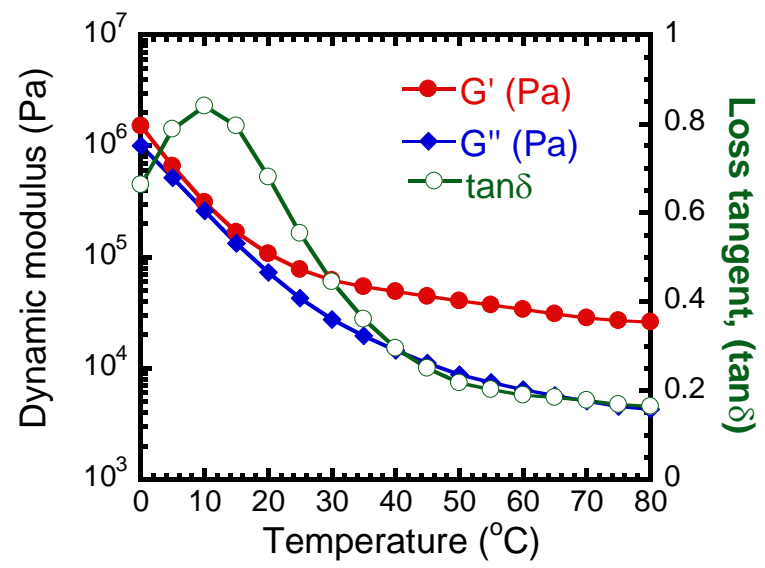

Figure 1. Temperature dependences of the properties of polyampholyte hydrogel PA-0.1.

a, Optical transmittance at $578 \mathrm{~nm}$ upon heating $(\Delta)$ and cooling $(\nabla)$. b, Dynamic temperature sweep test of storage modulus $\mathrm{G}^{\prime}$, loss modulus $\mathrm{G}^{\prime \prime}$, and $\tan \delta=G^{\prime \prime} / G^{\prime}$ measured at a constant strain of $0.5 \%$ and frequency $1.0 \mathrm{~Hz}$.

The $G^{\prime}$ was high $\left(>0.1 \mathrm{MPa}\right.$ ) at low temperature (below $10^{\circ} \mathrm{C}$ ) and it substantially decreased with the temperature increase. Within a temperature sweep between 0 to $80^{\circ} \mathrm{C}$, a peak in the tan $\delta$ appeared around $10^{\circ} \mathrm{C}$. These results suggest that the softening temperature of the sample is $T_{\mathrm{s}}=10{ }^{\circ} \mathrm{C}$, which is in agreement with the UCST value by transmittance measurement, and most of the ionic bonds are in very mobile state (weak bonds) around the room temperature. The PA- 0.1 sample has a wide mechanical spectrum with a $\tan \delta$ peak around the frequency of $\omega_{\max } \simeq 300 \mathrm{~Hz}$, which gives a characteristic relaxation time of $\mathrm{t}=1 /\left(2 \pi \omega_{\max }\right) \simeq 0.5 \mathrm{~ms}$ (Figure S1). So most of the weak bonds have exchange times around this time scale.

The weak bonds may participate in the self-healing at interface even in the ambient environment. This is confirmed in Figure 2. The dumbbell shaped sample PA-0.1 (Fig. 2a (i)) was cut into two pieces in the middle with a razor blade. One piece was dyed by immersing 
in allura blue solution for $1 \mathrm{~min}$ for better visualization (Fig. 2a (ii)). After that, the two cut surfaces were brought in contact with a slight pressure at room temperature in air (Supplementary Movie S1). It was amazing to observe that the two pieces healed immediately, as revealed by the bending deformation of the sample right after the contact (Fig. 2a (iii and iv)). For prolonged mending, the sample was placed in a rubber frame having a size just fitting the sample pieces and the frame was immersed in water at $25^{\circ} \mathrm{C}$ for further mending. The healing progressed with time and the scar of the cutting was hardly recognizable after $24 \mathrm{~h}$ (Supplementary Movie S2). The mended sample was able to sustain large tensile strain of more than $1000 \%$ (Fig. 2a (v)) and to recover its shape and size when stress was released (Supplementary Movie S2). Owing to the high toughness, this sample permitted us to quantitatively evaluate the self-healing efficiency by comparing the tensile stress-strain curves of the virgin sample and the mended samples. The results for samples mended for different time at $25^{\circ} \mathrm{C}$ are shown in Figure $\mathbf{2 b}$. All of the stress-strain curves for the samples mended at different healing times overlapped with that of the virgin sample. Even for a relatively short healing time $(\sim 1 \mathrm{~h})$, the mended sample could be stretched up to about $500 \%$ strain without failure. Longer healing times led to better healing, and the failure strain for a healing time of $24 \mathrm{~h}$ reached $\sim 3000 \%$ that is close to the failure strain of the virgin sample. This indicates that the mended sample almost recovers to its original stress and strain. We observed that the crack initiated at the mended joint even after long healing times. This is understandable since some of the covalent bonds of this chemically crosslinked gel should be permanently ruptured by cutting, and the cut part became the weakest part of the sample. The healing efficiency can be characterized by comparing the mechanical performance of the mended samples with that of virgin samples in room temperature. Healing efficiency $\eta_{\mathrm{w}}$ in terms of the work of extension $W_{\text {ext }}$ for different mended times are shown in 
Figure 2c. $\eta_{\mathrm{w}}$ increases with the healing time and saturate to a value of $82.3 \pm 12.7 \%$ around $24 \mathrm{~h}$ for the samples mended at $25^{\circ} \mathrm{C}$.

\section{$\mathbf{a}$}

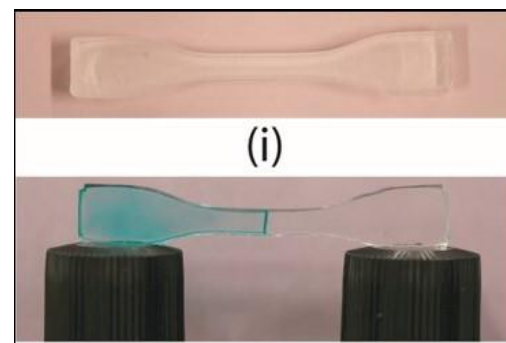

(iii) (ii)

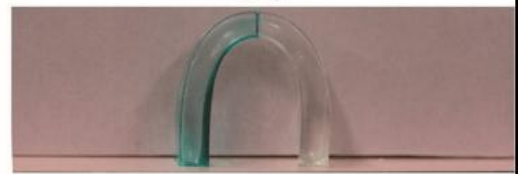

(iv)

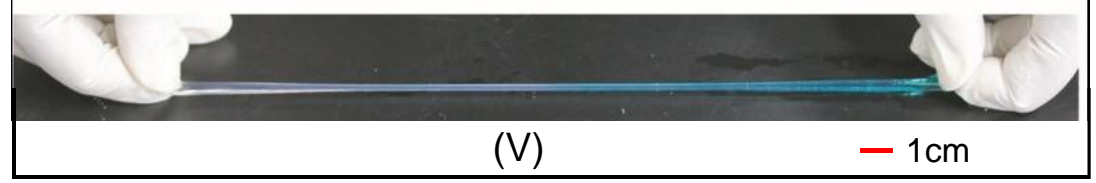

b

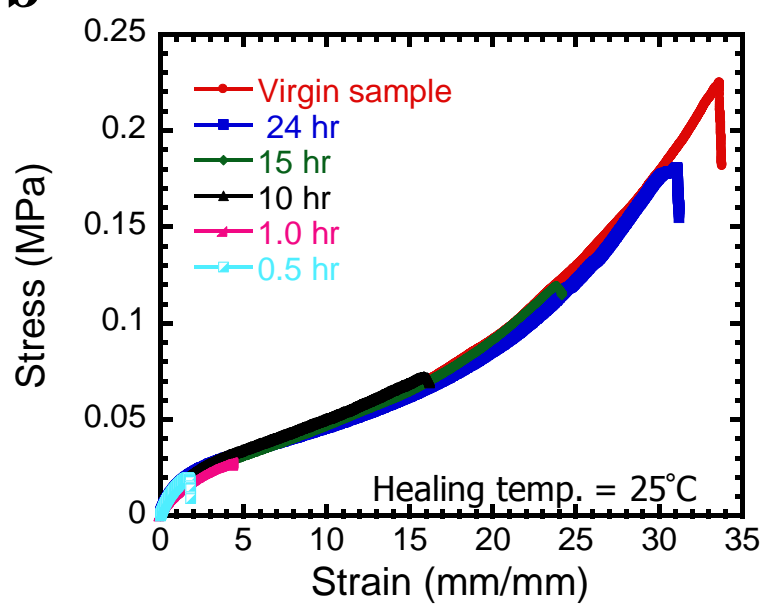

c

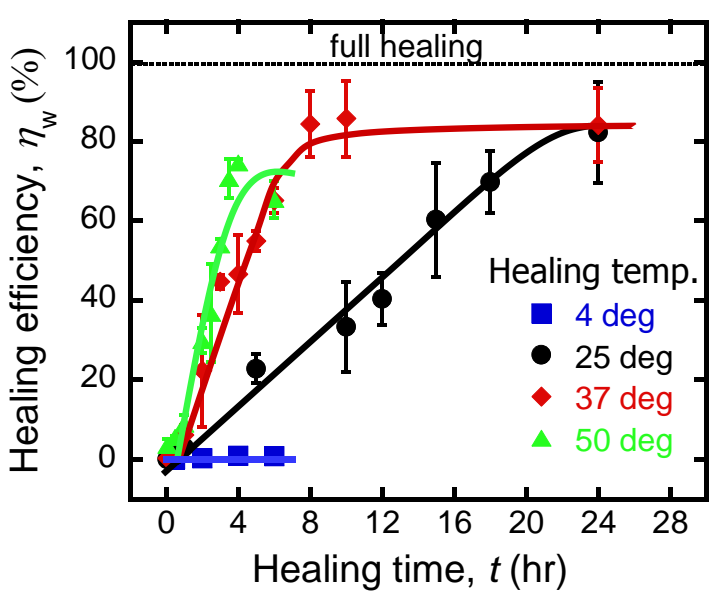

d

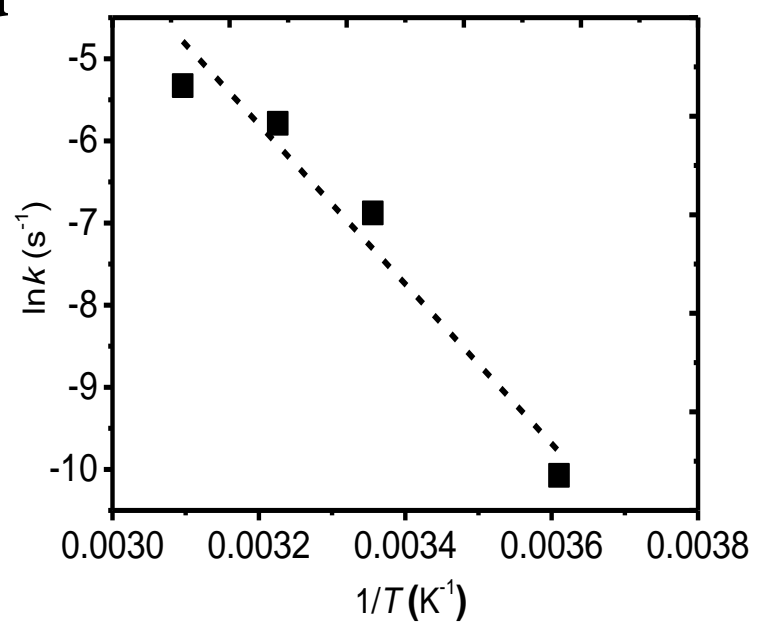

Figure 2. Self-healing behavior of polyampholyte hydrogel PA-0.1. a, Photographs of self-healing behavior of the sample at room temperature: (i) dumbbell shape virgin sample, (ii) 
after cutting and dyeing by immersing in allura blue solution for 1 minute, (iii) cut pieces were contacted in air, (iv) immediately bended after contact, (v) stretched to more than $1000 \%$ after $24 \mathrm{~h}$ healing in water at $25^{\circ} \mathrm{C}$. b, Typical stress-strain curves of the virgin sample and healed sample measured at room temperature. Cut pieces were contacted immediately after cutting and healed in water for different times at $25^{\circ} \mathrm{C}$. The strain rate was $0.011 \mathrm{~s}^{-1}$. c, Healing efficiency $\eta_{\mathrm{w}}$ at various healing times for samples healed at different temperatures. $\mathbf{d}$, Arrhenius plot depicting the temperature $T$ dependence of the healing rate $k$. Error bars in (c) are standard deviations for at least 5 samples.

We consider that the weak ionic bonds that have a relatively short bond-exchange time act as active sites and are responsible for the self-healing. The life time of the ionic bonds and the density of the weak bonds are related to the relative bond strength that is the ratio of bond association energy to thermal energy $k_{\mathrm{B}} T$. Thus, changing the mending temperature will change the relative bond strength and therefore the self-healing behaviors. To see the temperature effect, the mending was performed at different temperatures. The healing occurred more quickly at high temperature $\left(37^{\circ} \mathrm{C}, 50^{\circ} \mathrm{C}\right)$. On the other hand, healing below the softening temperature $\left(T_{\mathrm{s}}=10^{\circ} \mathrm{C}\right)$ of the sample hardly occurred, and the healing efficiency at $4^{\circ} \mathrm{C}$ was only $\sim 1 \%$ after 6 hours saturated healing (Fig. 2c). The fast healing kinetics at elevated healing temperature is the result of the fast bond exchange rate at a high temperature. Above the softening temperature, most of the ionic bonds serve as weak bonds that participate in the quick healing and energy dissipation. Gels in soft state also favor the formation of a full contact between the cut surfaces. Thus, we observed quick healing at elevated temperatures. The poor healing efficiency below the softening temperature is the result of increased bond exchange time, which suppresses the motion of polymer segments. Below the softening temperature $\left(T_{\mathrm{s}}=10^{\circ} \mathrm{C}\right)$, the relative bond strength becomes very high and 
most of the ionic bonds behave as strong bonds with a very long bond exchange time. This gives two negative effects on the healing. On molecular scale, a long bond exchange time substantially reduces the bond reforming probability. In other words, most of the ionic bonds belong to strong bonds, and the density of weak bonds substantially decreases in this case. On mesoscopic scale, a long bond exchange time substantially increases the modulus of the gel, which is unfavorable to form full contact of the two surfaces. For the second effect, an empirical criterion, known as Dahlquist criteria, says that the critical elastic modulus for a material to show good adhesion should be less than $0.1 \mathrm{MPa} .{ }^{31}$ Materials with elastic moduli exceeding $10^{5} \mathrm{~Pa}$ have poor adhesion due to the inability to form good contact with a surface. The poor healing efficiency at $4^{\circ} \mathrm{C}$, at which the sample became rigid with a storage modulus of $G^{\prime} \sim 0.7 \mathrm{MPa}$, is in consistent with the Dahlquist criteria.

The self-healing kinetics should be related to the kinetics of weak bond association, and the healing kinetic rate $k$ at a certain temperature can be estimated from the slope of the healing efficiency against the healing time in the linear region. The $\ln k$ linearly decreases with the inverse of the healing temperature $T$ (Fig. 2d), which indicates that the healing is an Arrhenius process, following the equation, $k=\mathrm{A} e^{-E_{a} / k_{B} T}$, where $E_{a}$ is the activation energy, $A$ is the frequency factor for the healing reaction, $k_{B}$ is the Boltzmann constant. ${ }^{32}$ This means that the weak bonds should overcome the energy barrier $E_{a}$ to participate in the self-healing process. The $E_{a}$ value $\left(\sim 79.2 \mathrm{~kJ} / \mathrm{mol}=32 k_{B} T\right.$ of room temperature) estimated from Fig. 2 d is lower than the lower bound of $E_{a}$ determined from the dynamic rheological measurement (96 222 kJ/mol) (Supplementary Figure S1). This result suggests that the weak bonds on the cut surfaces have a lower energy barrier to reform than those in the bulk.

\section{Effect of cross-linker density}


We assume that the less than $100 \%$ healing of PA- 0.1 sample is due to the presence of the non-dynamic bonds, including the strong bonds that have bond exchange times longer than the healing time, the chemical crosslinking, and the trapped entanglement. The strong bonds will transform to weak bonds at high temperature, and participate in healing after rupture. However, the chemical crosslinking and the trapped entanglement, once being ruptured, cannot reform permanently even at elevated temperature. To enhance the self-healing efficiency, one needs to decrease the amount of these non-dynamic bonds, in sacrificing the modulus and strength of the material at large time scale.

Figure 3 shows the mechanical behaviors of the PA-C $\mathrm{C}_{\mathrm{MBAA}}$ samples with different chemical cross-linker densities $\mathrm{C}_{\mathrm{MBAA}}$. The large amount of $\mathrm{C}_{\mathrm{MBAA}}(>0.1 \mathrm{~mol} \%)$ substantially limited the extensibility of the polymer strands, leading to a smaller fracture strain $\varepsilon_{\mathrm{b}}$ (Figure 3a). For the same strain, the stress rapidly increased for samples of high $\mathrm{C}_{\mathrm{MBAA}}$, leading to an increase in the elastic modulus of the samples (Figure 3b). It should be noted that in contrast to these dramatic changes in the mechanical behaviors as a function of $C_{\mathrm{MBAA}}$, the water content of the gel hardly changed with $\mathrm{C}_{\mathrm{MBAA}}$ (Table 1). This indicates that the chemical cross-linker stabilizes the ionic bonds and as a result, the density of strong bonds also increases at the enhanced chemical cross-linker density.

The non-crosslinked sample PA-0 showed an average healing efficiency of $\eta_{w}=$ $91.98 \pm 7.11 \%$, which is higher than that of PA- 0.1 (Table 1). The highest $\eta_{w}$ of PA-0 sample could reach 99\% (Figure 3c). Inversely, increasing of the chemical cross-linker densities $\mathrm{C}_{\mathrm{MBAA}}$ dramatically reduced the self-healing efficiency (Figures $\mathbf{3 d}$, 3e and $\mathbf{3 f}$ ). The selfhealing efficiency $\eta_{\mathrm{w}}, \eta_{\sigma}$, and $\eta_{\varepsilon}$ for PA- $\mathrm{C}_{\mathrm{MBAA}}$ samples are summarized in Table 1 . The reduction in healing efficiency at high $C_{\mathrm{MBAA}}$ could be attributed to the formation of large amount of nondynamic bonds, which is revealed by the substantial increase in the Young's modulus $E$ (Figure 3b). Furthermore, the high modulus is unfavorable to form full contact of 
the two surfaces, and substantially reduces the bond reforming probability across interface, leading to the poor self-healing efficiency.

Table 1. Self-healing results of polyampholyte hydrogels

\begin{tabular}{|c|c|c|c|c|c|c|c|c|c|c|}
\hline \multirow{2}{*}{ 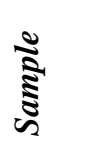 } & \multirow{2}{*}{$\underbrace{\stackrel{0}{3}}_{0}$} & \multicolumn{3}{|c|}{ Virgin } & \multicolumn{3}{|c|}{ Mended } & \multicolumn{3}{|c|}{ Healing efficiency } \\
\hline & & $\begin{array}{l}\sigma_{\mathrm{b}} \\
(\mathrm{MPa})\end{array}$ & $\begin{array}{l}\varepsilon_{\mathrm{b}} \\
(\mathrm{m} / \mathrm{m})\end{array}$ & $\begin{array}{l}W_{\text {ext }} \\
\left(\mathrm{MJ} / \mathrm{m}^{3}\right)\end{array}$ & $\begin{array}{l}\sigma_{\mathrm{b}} \\
(M P a)\end{array}$ & $\begin{array}{l}\varepsilon_{\mathrm{b}} \\
(\mathrm{m} / \mathrm{m})\end{array}$ & $\begin{array}{l}W_{\text {ext }} \\
\left(\mathrm{MJ} / \mathrm{m}^{3}\right)\end{array}$ & $\begin{array}{l}\eta_{\mathrm{w}} \\
(\%)\end{array}$ & $\begin{array}{l}\eta_{\sigma} \\
(\%)\end{array}$ & $\begin{array}{l}\eta_{\varepsilon} \\
(\%)\end{array}$ \\
\hline $\begin{array}{l}\text { PA- } \\
0\end{array}$ & $\begin{array}{l}52.42 \\
\pm 2.49\end{array}$ & $\begin{array}{l}0.19 \\
\pm 0.002\end{array}$ & $\begin{array}{l}17.18 \\
\pm 0.43\end{array}$ & $\begin{array}{l}1.50 \\
\pm 0.08\end{array}$ & $\begin{array}{l}0.17 \\
\pm 0.01\end{array}$ & $\begin{array}{l}15.93 \\
\pm 0.32\end{array}$ & $\begin{array}{l}1.39 \\
\pm 0.02\end{array}$ & $\begin{array}{l}91.98 \\
\pm 7.11\end{array}$ & $\begin{array}{l}89.41 \\
\pm 5.91\end{array}$ & $\begin{array}{l}92.11 \\
\pm 4.78\end{array}$ \\
\hline $\begin{array}{l}\text { PA- } \\
0.1\end{array}$ & $\begin{array}{l}50.43 \\
\pm 0.26\end{array}$ & $\begin{array}{l}0.21 \\
\pm 0.01\end{array}$ & $\begin{array}{l}32.64 \\
\pm 1.17\end{array}$ & $\begin{array}{l}2.80 \\
\pm 0.26\end{array}$ & $\begin{array}{l}0.17 \\
\pm 0.01\end{array}$ & $\begin{array}{l}28.36 \\
\pm 1.27\end{array}$ & $\begin{array}{l}2.27 \\
\pm 0.14\end{array}$ & $\begin{array}{l}82.26 \\
\pm 12.72\end{array}$ & $\begin{array}{l}80.71 \\
\pm 12.67\end{array}$ & $\begin{array}{l}88.05 \\
\pm 7.80\end{array}$ \\
\hline $\begin{array}{l}\text { PA- } \\
0.3\end{array}$ & $\begin{array}{l}48.37 \\
\pm 0.33\end{array}$ & $\begin{array}{l}0.35 \\
\pm 0.02\end{array}$ & $\begin{array}{l}11.35 \\
\pm 0.74\end{array}$ & $\begin{array}{l}1.53 \\
\pm 0.23\end{array}$ & $\begin{array}{l}0.20 \\
\pm 0.01\end{array}$ & $\begin{array}{l}7.46 \\
\pm 0.22\end{array}$ & $\begin{array}{l}0.68 \\
\pm 0.07\end{array}$ & $\begin{array}{l}50.14 \\
\pm 13.66\end{array}$ & $\begin{array}{l}56.50 \\
\pm 6.84\end{array}$ & $\begin{array}{l}66.99 \\
\pm 7.46\end{array}$ \\
\hline $\begin{array}{l}\text { PA- } \\
1.0\end{array}$ & $\begin{array}{l}47.33 \\
\pm 0.45\end{array}$ & $\begin{array}{l}0.54 \\
\pm 0.13\end{array}$ & $\begin{array}{l}6.58 \\
\pm 0.48\end{array}$ & $\begin{array}{l}1.31 \\
\pm 0.25\end{array}$ & $\begin{array}{l}0.13 \\
\pm 0.01\end{array}$ & $\begin{array}{l}2.53 \\
\pm 0.32\end{array}$ & $\begin{array}{l}0.24 \\
\pm 0.04\end{array}$ & $\begin{array}{l}22.13 \\
\pm 8.82\end{array}$ & $\begin{array}{l}28.95 \\
\pm 11.98\end{array}$ & $\begin{array}{l}38.72 \\
\pm 9.23\end{array}$ \\
\hline $\begin{array}{l}\text { PA- } \\
2.0\end{array}$ & $\begin{array}{l}49.63 \\
\pm 1.85\end{array}$ & $\begin{array}{l}0.55 \\
\pm 0.18\end{array}$ & $\begin{array}{l}3.97 \\
\pm 0.09\end{array}$ & $\begin{array}{l}0.93 \\
\pm 0.23\end{array}$ & $\begin{array}{l}0.11 \\
\pm 0.01\end{array}$ & $\begin{array}{l}1.17 \\
\pm 0.25\end{array}$ & $\begin{array}{l}0.13 \\
\pm 0.04\end{array}$ & $\begin{array}{l}19.17 \\
\pm 10.27\end{array}$ & $\begin{array}{l}24.56 \\
\pm 11.95\end{array}$ & $\begin{array}{l}28.81 \\
\pm 8.42\end{array}$ \\
\hline $\begin{array}{l}\text { PA- } \\
4.0\end{array}$ & $\begin{array}{l}50.13 \\
\pm 0.70\end{array}$ & $\begin{array}{l}0.40 \\
\pm 0.08\end{array}$ & $\begin{array}{l}1.33 \\
\pm 0.10\end{array}$ & $\begin{array}{l}0.28 \\
\pm 0.08\end{array}$ & $\begin{array}{l}0.001 \\
\pm 0.01\end{array}$ & $\begin{array}{l}0.13 \\
\pm 0.02\end{array}$ & $\begin{array}{l}0.002 \\
\pm 0.003\end{array}$ & $\begin{array}{l}4.03 \\
\pm 4.01\end{array}$ & $\begin{array}{l}4.62 \\
\pm 4.43\end{array}$ & $\begin{array}{l}10.25 \\
\pm 3.06\end{array}$ \\
\hline $\begin{array}{l}\mathbf{P A} *- \\
\mathbf{0}\end{array}$ & $\begin{array}{l}54.3 \\
\pm 0.01\end{array}$ & $\begin{array}{l}1.62 \\
\pm 0.10\end{array}$ & $\begin{array}{l}7.44 \\
\pm 0.33\end{array}$ & $\begin{array}{l}6.41 \\
\pm 0.31\end{array}$ & $\begin{array}{l}0.01 \\
\pm 0.01\end{array}$ & $\begin{array}{l}0.20 \\
\pm 0.04\end{array}$ & $\begin{array}{l}0.001 \\
\pm 0.001\end{array}$ & $\begin{array}{l}0.02 \\
\pm 0.01\end{array}$ & $\begin{array}{l}0.94 \\
\pm 0.92\end{array}$ & $\begin{array}{l}2.76 \\
\pm 0.71\end{array}$ \\
\hline
\end{tabular}

PA and PA* represent P(NaSS-co-DMAEA-Q) and P(NaSS-co-MPTC) polyampholyte hydrogel, respectively. Samples are coded as PA- $C_{\mathrm{MBAA}}$, where $C_{\mathrm{MBAA}}$ indicates the chemical cross-linker density (mol\%). The error ranges are the standard deviation from at least 5 samples. Self-healing experiments were performed at $25^{\circ} \mathrm{C}$ for $24 \mathrm{~h}$ in water. 
$\mathbf{a}$

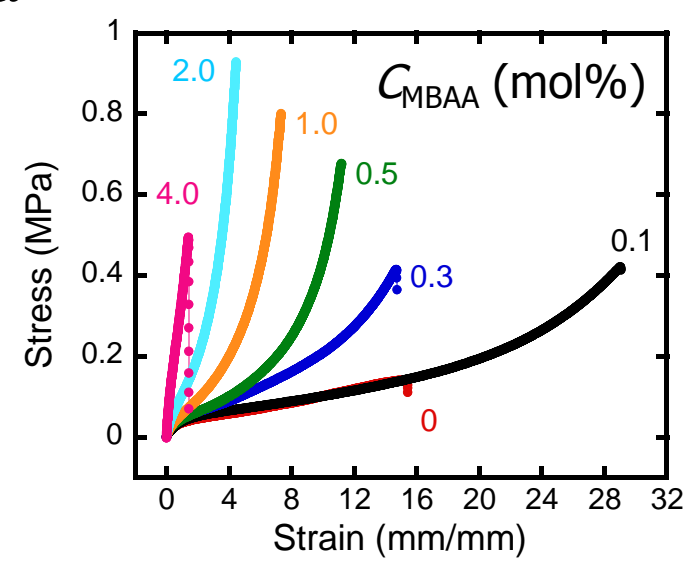

c

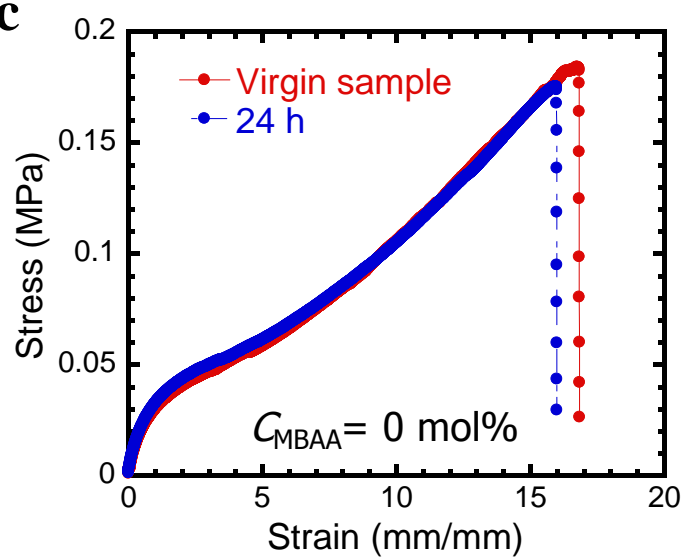

e

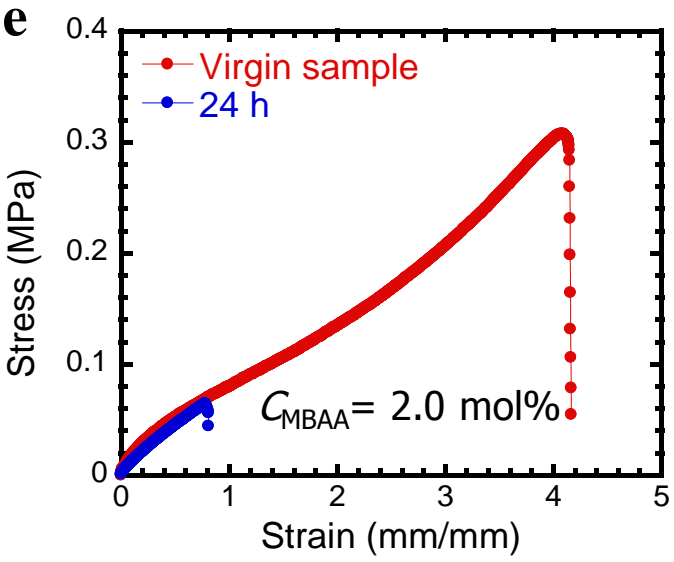

b
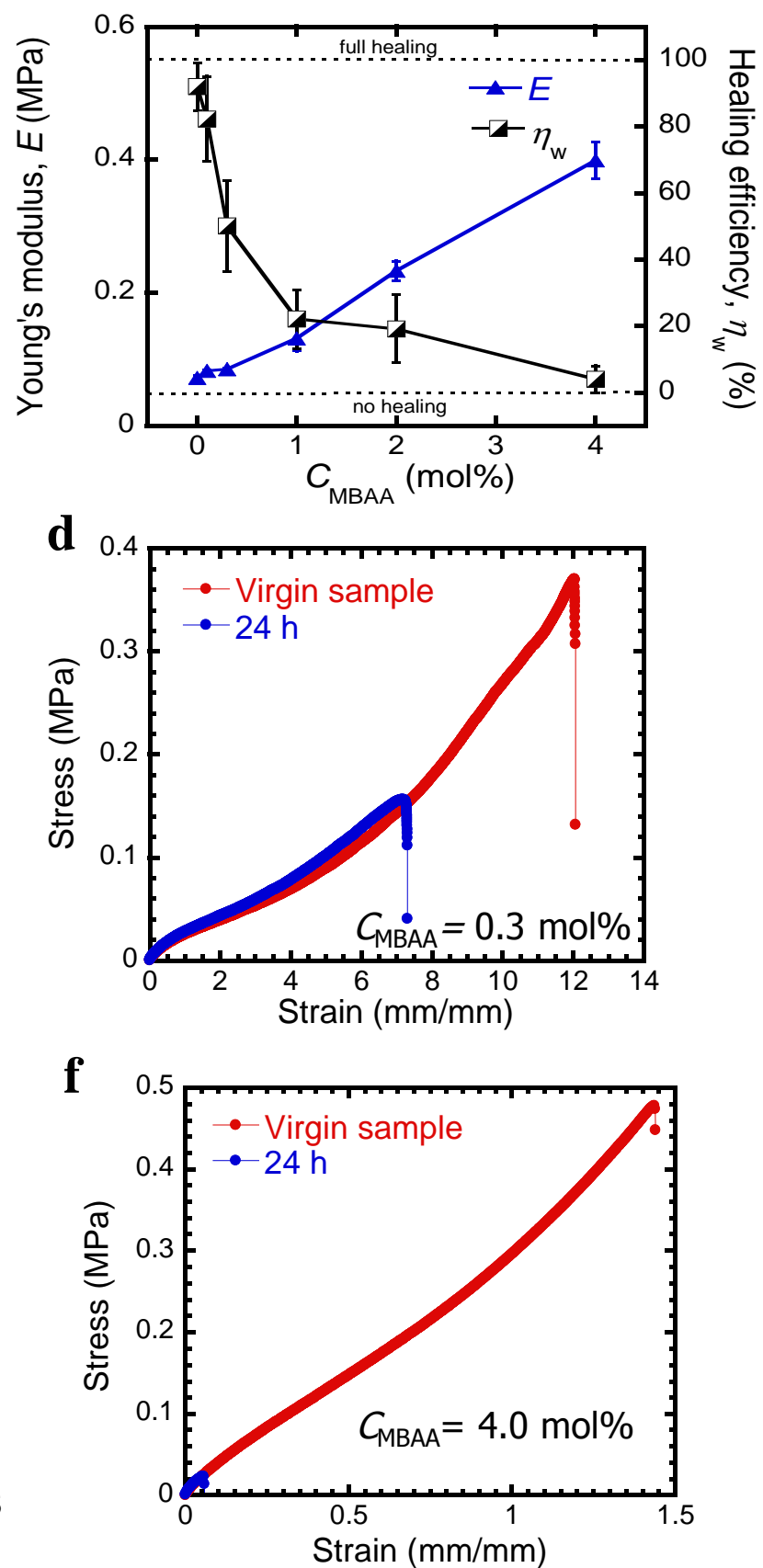

Figure 3. Effect of chemical cross-linker density $C_{\mathrm{MBAA}}(\mathrm{mol} \%)$ on the self-healing behaviors of polyampholyte hydrogels PA- $\boldsymbol{C}_{\text {MBAA }}$. a, Stress-strain curves of virgin samples with different $C_{\text {MBAA }}$ b, Young's modulus $E$ and healing efficiency $\eta_{\mathrm{w}}$ after 24 h healing at $25^{\circ} \mathrm{C}$ in water. Stress-strain behavior of virgin samples and the self-healed samples of P(NaSS-co-DMAEA-Q) (PA- $\left.C_{\mathrm{MBAA}}\right)$ with different $C_{\mathrm{MBAA}}, \mathbf{c}(0 \%), \mathbf{d}(0.3 \%), \mathbf{e}(2.0 \%)$ and $\mathbf{f}$ 
(4.0\%), respectively. All the measurements were performed at room temperature at a strain rate $0.011 \mathrm{~s}^{-1}$. Error bars in (b) are standard deviations for at least 5 samples.

Effect of chemical structure of monomers

a

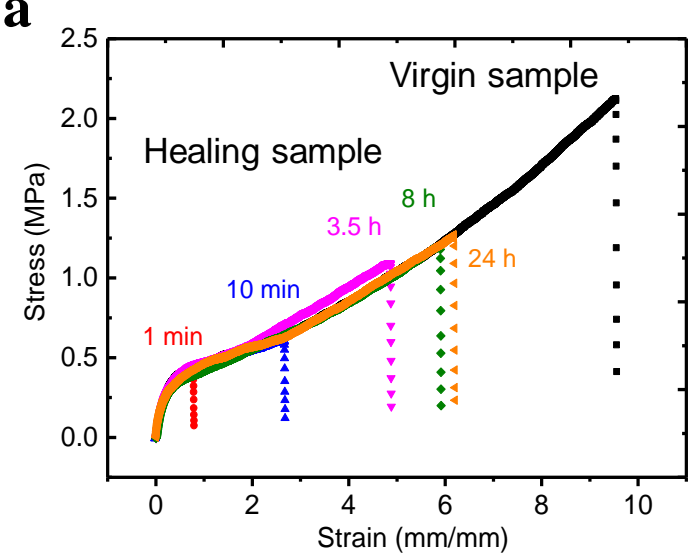

b

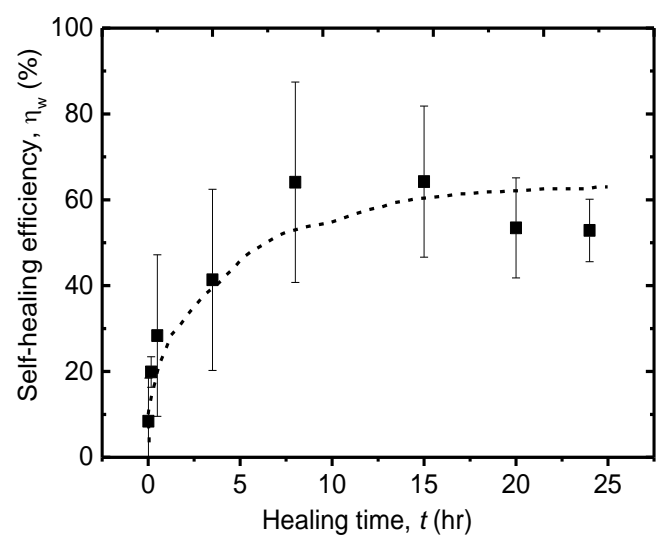

Figure 4. Effect of chemical structure on the self-healing behaviors of polyampholyte hydrogels $\mathrm{PA}^{*}-0$. a, Typical stress-strain curves of the virgin sample and self-healing samples healed at $55^{\circ} \mathrm{C}$ for different time. The tensile measurements were carried out at room temperature at a strain rate of $0.14 \mathrm{~s}^{-1}$. b. Healing efficiency $\eta_{\mathrm{w}}$ at various healing times $t$ for samples healed at $55^{\circ} \mathrm{C}$.

Previous studies have shown that the chemical structure of monomers substantially influence the mechanical behavior of polyampholyte hydrogels. Physical hydrogel from linear poly(NaSS-co-MPTC), denoted as $\mathrm{PA}_{-}^{*} 0$ in this study, was much rigid at room temperature than that of PA-0 from linear P(NaSS-co-DMAEA-Q). The PA*-0 has a softening temperature at $48.2^{\circ} \mathrm{C}$, much higher than that of PA-0 that has a softening temperature at $17.2^{\circ} \mathrm{C}^{27}$ This difference comes from the more hydrophobicity of the MPTC monomer, which stabilizes the ionic bonds in comparison to DMAEA-Q monomer. 
Here we also studied the self-healing of a physical poly(NaSS-co-MPTC) hydrogel. The

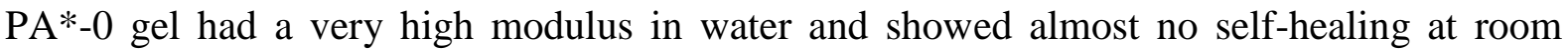
temperature (Table 1). While, the $\mathrm{PA}^{*}-0$ gel became soft at high temperature $\left(55^{\circ} \mathrm{C}\right)$ and showed enhanced self-healing efficiency (Figure 4). In similar to PA-0 gel, all of the stressstrain curves of $\mathrm{PA}^{*}-0$ gel mended at different healing times under $55^{\circ} \mathrm{C}$ water environment overlapped with that of the virgin sample (Figure 4a). The results of $\eta_{w}$ for different mended times are shown in Figure $\mathbf{4 b}$, and $\eta_{\mathrm{w}}$ increased with the healing time and saturated to a value of $64.1 \pm 23.1 \%$ around $8 \mathrm{~h}$. The relatively poor self-healing behavior of the PA*-0 should be related to the presence of large amount of strong bonds due to strong ionic interaction between NaSS and MPTC in comparison with that between NaSS and DMAEA-Q.

\section{Discussions}

The above results have revealed that self-healing efficiency is mainly related to the density of dynamic weak bonds that have bond exchange time shorter than the healing time and the stiffness of the samples. The high density of weak bonds gives a high bond reforming probability to participate the self-healing process, and a very soft sample favors a good contact across the interface, giving the positive effect on the self-healing efficiency.

First, we try to discuss, quantitatively, the correlation between the self-healing efficiency and the weak bonds fraction in relative to the total bonds. The latter can be estimated from the ratio of transient modulus that changes with time to the total modulus of the sample. The contributions from the transient, dynamic bonds and the non-dynamic bonds can be estimated from the tensile stress-strain curves of the samples using a viscoelastic model proposed by

Creton et al ${ }^{30,33}$. The model consists of a parallel combination of the Upper Convected Maxwell (UCM) model for the description of viscoelastic flow and Gent strain hardening model for the entropic elasticity of finite extensibility of polymer chains. Our previous study 
has shown that this viscoelastic model well describes the viscoelastic features of polyampholyte hydrogels. ${ }^{30}$ Using this model, we can separate the shear modulus of the viscoelastic part, $G_{v}$, stemming from the contribution of weak inter-chain bonds that rupture during deformation, and the shear modulus of the elastic part, $G_{e}$, stemming from the contributions of non-dynamic bonds that do not flow during the deformation (Supporting Information, Figure S2). It should be noted that both $G_{v}$ and $G_{e}$ depend on the observation time.

The parameters $G_{e}$ and $G_{v}$ determined by fitting the tensile behaviours of gels with different $C_{\mathrm{MBAA}}$ are summarized in Figure 5. We found that an increasing in $C_{M B A A}$ enhanced $G_{\mathrm{e}}$ while $G_{v}$ kept a constant (Figure 5a). Therefore, increase in $C_{M B A A}$ leads to a decrease in the value of $G_{\mathrm{v}} / G_{\mathrm{e}}$, which indicates a decrease in the density ratio of dynamic bonds (weak bonds) to non-dynamic bonds (Figure 5b). In addition, the $G_{\mathrm{e}}$ scales with the $C_{\mathrm{MBAA}}$ stronger than linear, indicating that the chemical crosslinking enhances the formation of strong bonds, and the enhanced $G_{e}$ stems from the increase in chemical crosslinking density and strong interchain bonds.

To discuss the effect of temperature and the chemical structure on the self-healing behavior, we also fit the tensile behaviors of PA-0.1 and PA*-0 samples at different healing temperatures, and the parameters are summarized in Supplementary Table S1. Both of $G_{\mathrm{e}}$ and $G_{\mathrm{v}}$ increased with the decrease of the healing temperature. This result should be attributed to the increase of the relative bond strength at the low temperature.

If the healing can only occur by the reforming of dynamic weak bonds across the interface, the self-healing efficiency can be correlated to the fraction of dynamic weak bonds in the total bonds, which can be estimated from $G_{v} /\left(G_{e}+G_{v}\right)$. Therefore, we plot the saturated healing efficiency $\eta_{w}$ agianst $G_{v} /\left(G_{e}+G_{v}\right)$. Figure 6 shows that except for the points PA-0.1 $\left(4^{\circ} \mathrm{C}\right)$ and $\mathrm{PA}^{*}-0\left(25^{\circ} \mathrm{C}\right)$, all the data show a positive correlation between $\eta_{w}$ and $G_{v} /\left(G_{e}+G_{v}\right)$, 
regardless of the differences in samples formulation (crosslinker density and chemical structure) and the mending temperature.

When comparing the experimental results with the linear regression in Figure 6, some factors should be considered. One is the under-estimation of the $G_{v} /\left(G_{e}+G_{v}\right)$. Even for the sample mended and measured at the same room temperature, the observation time scale of the tensile test ( 100 s for PA samples and $\sim 10 \mathrm{~s}$ for $\mathrm{PA}^{*}$ sample) is much shorter than the mending time $(24 \mathrm{~h})$, therefore dynamic bonds with much longer bond exchange times than the observation time but shorter than the mending time was accounted as the elastic component, which leads to under-estimation of $G_{v} /\left(G_{e}+G_{v}\right)$. This will give a positive deviation of the data points from the linear regression in Figure 6. To eliminate this factor, $G_{v} /\left(G_{e}+G_{v}\right)$ should be estimated from the long term relaxation modulus spectra. This should be discussed in future work. Another is the contact of the interfaces at the molecular level. Due to finite surface roughness, the cut surfaces might be in non-full contact. This will give a negative deviation of the data points from the linear regression in Figure 6. The partial contact effect might exist even for relatively soft samples. Further work with well-controlled full contact should be performed. The prominent deviation of the data for samples PA- 0.1 mended at $4{ }^{\circ} \mathrm{C}$ and $\mathrm{PA}{ }^{*}-$ 0 mended at $25^{\circ} \mathrm{C}$ should apparently be attributed to the poor contact effect due to their very high rigidity (modulus of PA- $0.1\left(4^{\circ} \mathrm{C}\right)$ and $\mathrm{PA}^{*}-0\left(25^{\circ} \mathrm{C}\right)$ were $2.8 \mathrm{MPa}$ and $1.8 \mathrm{MPa}$, respectively).

The above results indicate clearly that the self-healing is due to reforming of dynamic weak. For soft hydrogels that can form a good contact at the interface, the self-healing efficiency is related to the fraction of the weak bonds to total bonds. 

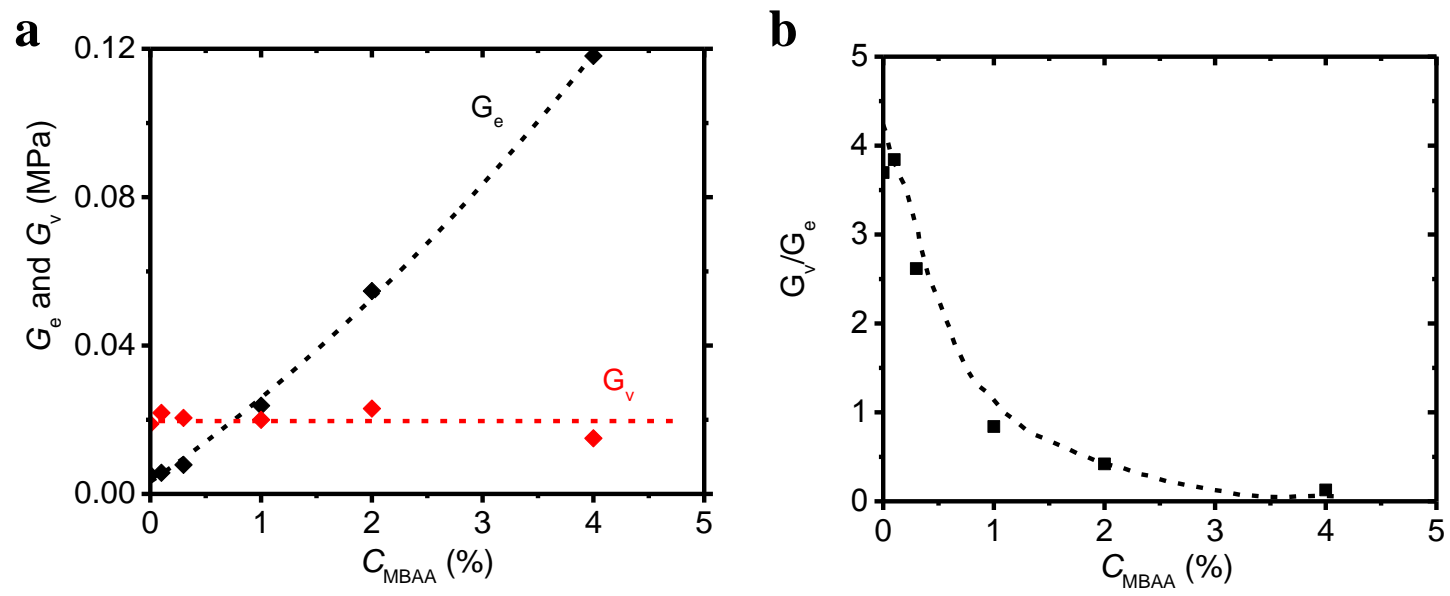

Figure 5. Chemical crosslinker density $C_{\mathrm{MBAA}}$ dependence of shear moduli of the elastic part $G_{\mathrm{e}}$ and viscoelastic part $G_{\mathrm{v}}(\mathbf{a})$, and the ratio of $G_{\mathrm{v}} / G_{\mathrm{e}}(\mathbf{b})$ for the hydrogels PA- $C_{\text {MBAA }}$.

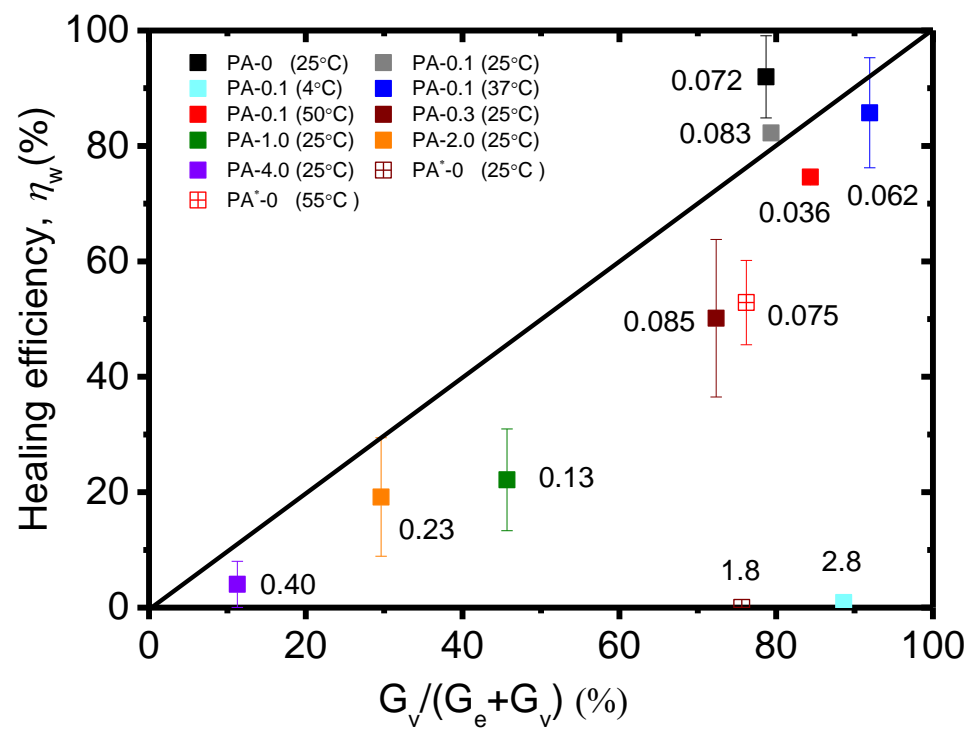

Figure 6. Relationship between self-healing efficiency $\eta_{w}$ and $G_{\mathrm{v}} /\left(G_{\mathrm{e}}+G_{\mathrm{v}}\right)$ for different polyampholyte hydrogels mended at different conditions. All the gels were healed in water and the healing temperatures are shown in figure. Numbers in the graph are the modulus (in $\mathrm{MPa}$ ) of the samples at the healing conditions.

\section{Conclusions}


Studies on the effects of the healing condition (temperature), and the chemistry (chemical crosslinker density and chemical structure of the monomers) on the self-healing behaviours of polyampholyte hydrogels at the fractured surfaces have revealed that the self-healing is due to the reforming of dynamic weak bonds, and the self-healing efficiency is related to the weak bonds fraction for the two surfaces in full contact. The existence of high density of weak bonds that have a short bond exchange time favors for the self-healing ability, whatever on molecular scale (by improving the bond reforming probability) or mesoscopic scale (by forming full contact of the two surfaces). As the complexity of self-healing mechanism, beside the molecular level interaction between ionic groups and the rigidity of hydrogel, other factor may play an important role for the self-healing behaviors, such as applied strain rate, contact pressure during the healing process, and so on. This work will give insight on how to tune the structure of the supramolecular hydrogels for reaching the self-healing, along with the high toughness, self-resilience.

\section{Supplementary Information}

Table S1 summarizes the fitted parameters. Figures S1-S2 show the dynamic behaviour and fitted parameters, respectively. Movies S1-S2 show the self-healing behaviour of polyampholyte hydrogels. This material is available free of charge via the Internet at http://pubs.acs.org.

\section{Acknowledgements}

This research was partially funded by a Grant-in-Aid for Scientific Research (S) (No. 124225006) from Japan Society for the Promotion of Science (JSPS). This research was also partially funded by ImPACT Program of Council for Science, Technology and Innovation (Cabinet Office, Government of Japan). A. B. I. thanks Mr. Koshiro Sato for help in drawing illustration and Ms. Mahmuda Nargis for valuable discussion. 


\section{Competing financial interests}

The authors declare no competing financial interests.

\section{References}

(1) Meyers, M. A.; Chen, P.-Y.; Lin, A. Y.-M.; Seki, Y. Biological materials: Structure and mechanical properties. Progress in Materials Science 2008, 53 (1), 1-206.

(2) Guo, S.; Dipietro, L. A. Factors affecting wound healing. Journal of dental research 2010, 89 (3), 219-229.

(3) White, S. R.; Blaiszik, B. J.; Kramer, S. L. B.; Olugebefola, S. C.; Moore, J. S.; Sottos, N. R. Self-healing polymers and composites. American Scientist 2011, 99 (5), 392-399.

(4) Akay, G.; Hassan-Raeisi, A.; Tuncaboylu, D. C.; Orakdogen, N.; Abdurrahmanoglu, S.; Oppermann, W.; Okay, O. Self-healing hydrogels formed in catanionic surfactant solutions. Soft Matter 2013, 9 (7), 2254.

(5) Hao, X.; Liu, H.; Xie, Y.; Fang, C.; Yang, H. Thermal-responsive self-healing hydrogel based on hydrophobically modified chitosan and vesicle. Colloid and Polymer Science 2013, 291 (7), 1749-1758.

(6) Haraguchi, K.; Uyama, K.; Tanimoto, H. Self-healing in nanocomposite hydrogels. Macromolecular Rapid Communications 2011, 32 (16), 1253-1258.

(7) Holten-Andersen, N.; Harrington, M. J.; Birkedal, H.; Lee, B. P.; Messersmith, P. B.; Lee, K. Y. C.; Waite, J. H. pH-induced metal-ligand cross-links inspired by mussel yield self-healing polymer networks with near-covalent elastic moduli. Proceedings of the National Academy of Sciences of the United States of America 2011, 108 (7), $2651-2655$.

(8) Jiang, G.; Liu, C.; Liu, X.; Zhang, G.; Yang, M.; Chen, Q.; Liu, F. Self-healing Mechanism and Mechanical Behavior of Hydrophobic Association Hydrogels with 
High Mechanical Strength. Journal of Macromolecular Science, Part A 2010, 47 (4), $335-342$.

(9) Kundu, S. K.; Matsunaga, T.; Yoshida, M.; Shibayama, M. Rheological study on rapid recovery of hydrogel based on oligomeric electrolyte. Journal of Physical Chemistry B 2008, $112(37), 11537-11541$.

(10) Mynar, J. L.; Aida, T. Materials science: the gift of healing. Nature 2008, 451 (February), 895-896.

(11) Phadke, A.; Zhang, C.; Arman, B.; Hsu, C.-C.; Mashelkar, R. A.; Lele, A. K.; Tauber, M. J.; Arya, G.; Varghese, S. Rapid self-healing hydrogels. Proceedings of the National Academy of Sciences of the United States of America 2012, 109 (12), 43834388.

(12) South, A. B.; Lyon, L. A. Autonomic self-healing of hydrogel thin films. Angewandte Chemie - International Edition 2010, 49 (4), 767-771.

(13) Tuncaboylu, D. C.; Sahin, M.; Argun, A.; Oppermann, W.; Okay, O. Dynamics and large strain behavior of self-healing hydrogels with and without surfactants. Macromolecules 2012, 45 (4), 1991-2000.

(14) Tuncaboylu, D. C.; Sari, M.; Oppermann, W.; Okay, O. Tough and self-healing hydrogels formed via hydrophobic interactions. Macromolecules 2011, 44 (12), 49975005.

(15) Varghese, S.; Lele, A.; Mashelkar, R. Metal-ion-mediated healing of gels. Journal of Polymer Science, Part A: Polymer Chemistry 2006, 44 (1), 666-670.

(16) Wang, Q.; Mynar, J. L.; Yoshida, M.; Lee, E.; Lee, M.; Okuro, K.; Kinbara, K.; Aida, T. High-water-content mouldable hydrogels by mixing clay and a dendritic molecular binder. Nature 2010, 463 (7279), 339-343.

(17) Zhang, H.; Xia, H.; Zhao, Y. Poly(vinyl alcohol) hydrogel can autonomously self-heal. 
ACS Macro Letters 2012, 1 (11), 1233-1236.

(18) Nakahata, M.; Takashima, Y.; Yamaguchi, H.; Harada, A. Redox-responsive selfhealing materials formed from host-guest polymers. Nature Communications 2011, 2, 511.

(19) Kakuta, T.; Takashima, Y.; Nakahata, M.; Otsubo, M.; Yamaguchi, H.; Harada, A. Preorganized hydrogel: Self-healing properties of supramolecular hydrogels formed by polymerization of host-guest-monomers that contain cyclodextrins and hydrophobic guest groups. Advanced Materials 2013, 25 (20), 2849-2853.

(20) Harada, A.; Takashima, Y. Macromolecular recognition and macroscopic interactions by cyclodextrins. Chemical Record 2013, 13 (5), 420-431.

(21) Zheng, Y.; Hashidzume, A.; Takashima, Y.; Yamaguchi, H.; Harada, A. Switching of macroscopic molecular recognition selectivity using a mixed solvent system. Nature Communications 2012, 3 (May), 831.

(22) He, L.; Fullenkamp, D. E.; Rivera, J. G.; Messersmith, P. B. pH responsive selfhealing hydrogels formed by boronate-catechol complexation. Chemical communications (Cambridge, England) 2011, 47 (26), 7497-7499.

(23) Deng, G.; Tang, C.; Li, F.; Jiang, H.; Chen, Y. Covalent cross-linked polymer gels with reversible sol-gel transition and self-healing properties. Macromolecules 2010, 43 (3), 1191-1194.

(24) Sun, J.-Y.; Zhao, X.; Illeperuma, W. R. K.; Chaudhuri, O.; Oh, K. H.; Mooney, D. J.; Vlassak, J. J.; Suo, Z. Highly stretchable and tough hydrogels. Nature 2012, 489 (7414), 133-136.

(25) Gong, J. P.; Katsuyama, Y.; Kurokawa, T.; Osada, Y. Double-network hydrogels with extremely high mechanical strength. Advanced Materials 2003, 15 (14), 1155-1158.

(26) Gong, J. P. Why are double network hydrogels so tough? Soft Matter 2010, 6 (12), 
2583.

(27) Sun, T. L.; Kurokawa, T.; Kuroda, S.; Ihsan, A. Bin; Akasaki, T.; Sato, K.; Haque, M. A.; Nakajima, T.; Gong, J. P. Physical hydrogels composed of polyampholytes demonstrate high toughness and viscoelasticity. Nature materials 2013, 12 (10), 932937.

(28) Ihsan, A. Bin; Sun, T. L.; Kuroda, S.; Haque, M. A.; Kurokawa, T.; Nakajima, T.; Gong, J. P. A phase diagram of neutral polyampholyte - from solution to tough hydrogel. Journal of Materials Chemistry B 2013, 1 (36), 4555-4562.

(29) Luo, F.; Sun, T. L.; Nakajima, T.; Kurokawa, T.; Zhao, Y.; Sato, K.; Ihsan, A. Bin; Li, X.; Guo, H.; Gong, J. P. Oppositely charged polyelectrolytes form tough, self-healing, and rebuildable hydrogels. Advanced Materials 2015, 27 (17), 2722-2727.

(30) Sun, T. L.; Luo, F.; Kurokawa, T.; Karobi, S. N.; Nakajima, T.; Gong, J. P. Molecular structure of self-healing polyampholyte hydrogels analyzed from tensile behaviors. Soft Matter 2015, 11, 9355-9366.

(31) Heddleson, S. S.; Hamann, D. d.; Lineback, D. R. The dahlquist criterion applicability of a rheological criterion to the loss of pressure sensitive tack in flour water dough. Cereal Chemistry. 1993, pp 744-748.

(32) Atkins, P.; De Paula, J. Physical Chemistry for the Life Sciences; Oxford University Press, UK, 2006; pp 238-264.

(33) Deplace, F.; Rabjohns, M.; Yamaguchi, T.; Foster, A.; Carelli, C.; Lei, C.-H.; Ouzineb, K.; Keddie, J.; Lovell, P.; Creton, C. Deformation and adhesion of a periodic soft-soft nanocomposite designed with structured polymer colloid particles. Soft Matter 2009, 5, $1440-1447$. 



\section{Table of Contents Graphic}

\section{Self-healing Behaviors of Tough Polyampholyte Hydrogels}

Abu Bin Ihsan $^{1 \S}$, Tao Lin Sun ${ }^{1,2,}$, Takayuki Kurokawa ${ }^{1,2}$, Sadia Nazneen Karobi ${ }^{3}$, Tasuku Nakajima $^{1,2}$, Takayuki Nonoyama ${ }^{1,2}$, Chanchal Kumar Roy ${ }^{1}$, Feng Luo ${ }^{1}$, Jian Ping Gong ${ }^{1,2 *}$

${ }^{1}$ Faculty of Advanced Life Science, Hokkaido University, Sapporo 060-0810, Japan

${ }^{2}$ Global Station for Soft Matter, Global Institution for Collaborative Research and Education (GI-CoRE), Hokkaido University, Sapporo 060-0810, Japan

${ }^{3}$ Graduate School of Life Science, Hokkaido University, Sapporo 060-0810, Japan

$\S:$ Authors equally contributed.

*: Author to whom correspondence should be addressed.

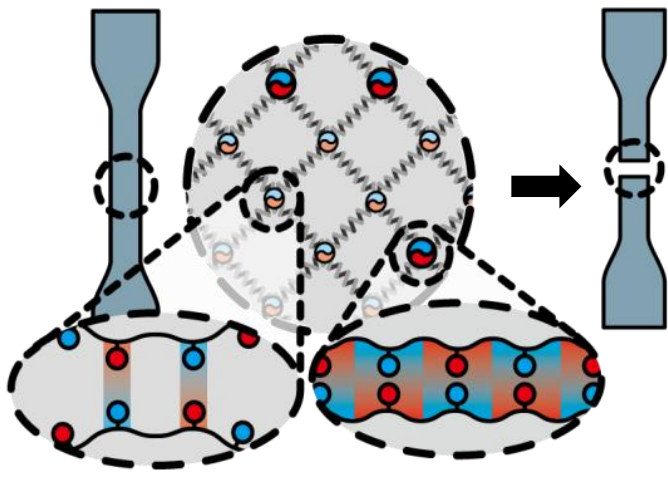

Virgin sample

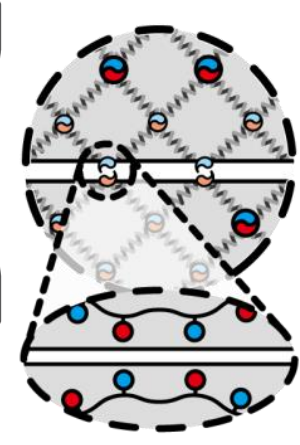

Cut sample

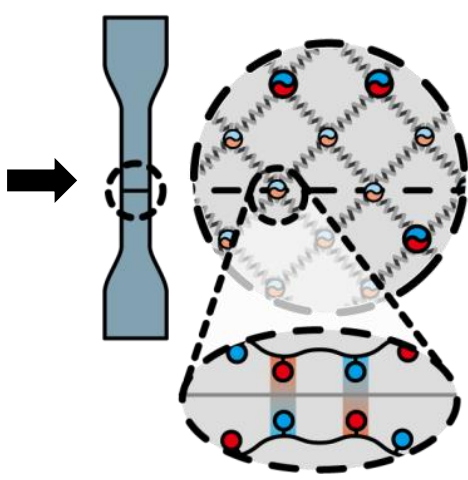

Healed sample
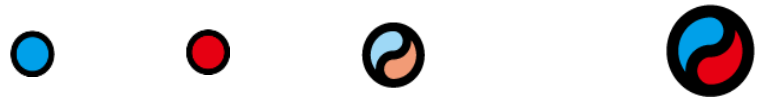

MMN

Anion Cation Weak bonds Strong bonds Polymer strand 